\title{
Computational Fluid Dynamics-Based Simulation of Crop Canopy Temperature and Humidity in Double-Film Solar Greenhouse
}

\author{
Wei Jiao, ${ }^{1,2}$ Qi Liu, ${ }^{1}$ Lijun Gao, ${ }^{1}$ Kunyu Liu, ${ }^{2}$ Rui Shi, ${ }^{3,4}$ and Na Ta ${ }^{1}$ \\ ${ }^{1}$ College of Mechanical and Electrical Engineering, Inner Mongolia Agricultural University, Hohhot 010018, China \\ ${ }^{2}$ Institute of Grassland Research of CAAS, Hohhot 010010, China \\ ${ }^{3}$ Collage of Grassland, Resources and Environment, Inner Mongolia Agricultural University, Hohhot 010018, China \\ ${ }^{4}$ Baotou Medical College, Baotou 014040, China
}

Correspondence should be addressed to Na Ta; jdtana@163.com

Received 24 July 2020; Revised 14 September 2020; Accepted 19 September 2020; Published 17 October 2020

Academic Editor: Yuan Li

Copyright ( 2020 Wei Jiao et al. This is an open access article distributed under the Creative Commons Attribution License, which permits unrestricted use, distribution, and reproduction in any medium, provided the original work is properly cited.

\begin{abstract}
The microenvironment of the crop area in a greenhouse is the main factor that affects its growth, quality, and pest control. In this study, we propose a double-layer film solar greenhouse microenvironment testing system based on computational fluid dynamics simulations of a celery canopy with a porous medium. A real greenhouse was examined with a sensor system for soil, air, radiation, and carbon dioxide detection to verify the simulation results. By monitoring the internal environment of celery canopies with heights of 0.8 and $1 \mathrm{~m}$ during a period of temperature fluctuations, we found the temperature and humidity of the canopy interior changed spatially and differed greatly from the those in the greenhouse under solar radiation conditions. The temperature and humidity of the celery canopy were $4-14^{\circ} \mathrm{C}$ lower and $10 \%-30 \%$ higher than those of the surroundings. As the canopy grew, the differences in temperature and humidity between the canopy and other parts of the greenhouse increased. The root mean square errors of the temperature and humidity with the $0.8 \mathrm{~m}$ high celery canopy were found to be 0.56 and 2.86 during the day and 0.24 and 0.81 at night, respectively; the corresponding values for the $1 \mathrm{~m}$ high celery canopy were found to be 0.51 and 2.26 during the day and 0.26 and 0.78 at night. The porous medium model expressed the temperature and humidity characteristics of the celery crop appropriately, and the simulation method was shown to be effective and feasible. With the simulation method proposed in this study, the production of crops in complex microenvironments in greenhouses can be modeled and digitized.
\end{abstract}

\section{Introduction}

Solar greenhouses are the most important type of greenhouse used in cold and arid areas of northern China [1]. They are either closed or semienclosed thermal systems and are composed of an enveloped structure, indoor air, crops, and soil. The environment in a solar greenhouse is affected by the external temperature, humidity, solar radiation intensity, wind speed, greenhouse structure, and planted crops [2]. The microenvironment in which a crop is grown affects the plant efficiency, healthy growth rate, pest control, greenhouse ventilation, irrigation, and other related aspects of the growth. The study of the temperature and humidity distribution in crop canopies is important for the crop production and quality [3-5]. However, research based on computa- tional fluid dynamics (CFD) simulations of a greenhouse has mainly focused on the greenhouse environment in relation to the crop growth demand [6-8]. With the rapid development of computer technology, CFD-based numerical simulations have been widely used to study the spatial and temporal distribution of climate-related characteristics (e.g., temperature) of microenvironments in greenhouses [9-12]. In recent years, more scholars have paid attention to the microenvironment of greenhouse crops. The changes in temperature and humidity inside greenhouses during crop growth has become a hot research topic [13-15]. Boulard and Roy used a CFD approach to model the micrometeorology of a closed greenhouse at the canopy level [16]. They visualized the distribution of solar radiation and found good agreement between the experimental and simulation 
measurements of crop transpiration. Tadj used the CFD method to simulate the microclimate in a closed vaulted greenhouse where tomatoes were grown and discussed the influence of different heating systems on the microclimate of tomatoes in the greenhouse [17]. Yue Zhang developed a method to evaluate the microlight climate and thermal performance of Liaoshen-type solar greenhouses, including a detailed 3D tomato canopy structure simulated using a functional-structural plant model [18]. Nebbali simulated the distributed climate parameters of a ventilated tunnel tomato greenhouse using a biband discrete ordinate (DO) model with the plant canopy considered a porous medium [19]. They considered the impact of the sun position and wind on the greenhouse microclimate.

In this study, we investigate the temperature and humidity distribution of a celery crop in a solar greenhouse with a double-layer cover film using the CFD method. We designed a contrasting experiment with two celery canopies of different heights set as isotropic porous media with different parameters. Then, we used the ANSYS Fluent to simulate the crop canopy temperature and humidity. A simple and efficient greenhouse sensor test system was designed to provide the boundary and verification conditions required for the simulation. The accuracy of the CFD model was verified by comparing the values obtained with the ANSYS Fluent with the measured results. Furthermore, we investigate the distribution of the temperature, and humidity in the celery crop canopies with different heights is explored.

\section{Materials and Methods}

2.1. Study Site and Sensor System Settings. The experiment was carried out at the Hailiutu solar greenhouse experimental site of the Inner Mongolia Agricultural University. The geographic coordinates were as follows: $40.68^{\circ} \mathrm{N}$ latitude and $111.37^{\circ}$ E longitude. Figure 1 shows the study site on the map of Hohhot and a photograph of the studied greenhouse.

The experiments were performed on a solar greenhouse with a double-layer cover film. The greenhouse faced south from the north and had a length of $70 \mathrm{~m}$ and a span of $9 \mathrm{~m}$. The back wall had a brick-and-soil structure and was $1.4 \mathrm{~m}$ thick and $3.5 \mathrm{~m}$ high. As shown in Figure 2, the greenhouse sensing detection system was composed of three parts: data acquisition, data storage, and data transmission [20]. Briefly, carbon dioxide (CD, model: $\mathrm{CD} 10$ ), air temperature and humidity (ATH, model: FLEX1000TH), solar radiation (SR, model: YJ-SR200), and soil temperature and moisture (STM, model: MS10) sensors, provided by Dalian Zheqin Technology Co., Ltd., were connected to a low-frequency half-duplex Lora serial port (LG207P) for data collection. The Lora data transmission terminal supports the point-topoint communication protocol with a working frequency band of 410-441 MHz. The computer server stored the collected data and was connected to the G780 data transmission module. The G780 is a product developed for the transmission of data between serial devices and network servers through the operator's network. Through simple attention command settings, the G780 can be used to achieve twoway serial transparent data transmission to the network.
The data were transferred to a laboratory analysis workstation through $4 \mathrm{G}$ wireless communication for the simulation analysis $[21,22]$.

The ATH sensors provide 14 bits air temperature (aTp) and 12 bits air humidity (aHd) measurements. The temperature measurement range was from -20 to $85^{\circ} \mathrm{C}$ with an accuracy of $\pm 0.3^{\circ} \mathrm{C}$. The humidity measurement range was from $0 \%$ to $100 \% \mathrm{RH}$ with an accuracy of $\pm 2 \% \mathrm{RH}$. The STM sensors measured temperatures between -40 and $80^{\circ} \mathrm{C}$ and humidity between 0 and $100 \% \mathrm{RH}$ with accuracies of \pm 0.5 and $\pm 3 \%$, respectively. The SR sensors measured the spectral range from 0.3 to $3 \mu \mathrm{m}$. The core device of the radiation sensor was a high-precision sensor, and a quartz glass cover made using precision optical cold processing was installed outside the sensor to effectively prevent environmental factors from affecting its performance. Figure 3 shows the arrangement of the measuring points in the solar greenhouse and a photograph of the greenhouse sensor system.

The outdoor temperature, humidity, solar radiation, wind speed, and wind direction were measured by the weather station. In order to focus on the crop canopy, groups of sensors were arranged at the center of the span cross-section of the crop canopy at a two-meter $(2 \mathrm{~m})$ distance on both sides. Each group consisted of four ATH sensors arranged in the vertical direction. These sensors could be adjusted according to the canopy height. Specifically, for a $0.8 \mathrm{~m}$ canopy height, the sensors could be adjusted to $0.1,0.4,0.6$, or $0.8 \mathrm{~m}$ from the ground level, and for a $1 \mathrm{~m}$ high canopy height, they can be adjusted to $0.1,0.4,0.8$, and $1 \mathrm{~m}$ from the ground level. Seven ATH sensors were arranged in the inner arch shed, inner membrane, outer membrane, north and south sides of the ceiling, two meters above the ceiling, and rear wall. These sensors were used to set the boundary conditions to observe aTp and aHd in the greenhouse. Three STM sensors were arranged on the soil surface layer to set the boundary conditions of the soil surface temperature and moisture content. The SR sensors were arranged in air and inside the canopy to observe the radiation of the sun inside the greenhouse. The CD sensors were arranged in the middle of the canopy and approximately $1.9 \mathrm{~m}$ above the ground to observe changes in the carbon dioxide concentration in the canopy and air.

2.2. CFD Model Procedure. The CFD simulation of the greenhouse energy dynamics is primarily based on the porous medium model, air turbulence model, solar radiation model, and energy component transport model [23]. Porous media consist of a combination of heterogeneous materials, in which solids serve as the backbone of the media, and liquids or gases are dispersed through the pores. In this study, the celery canopy was set as an isotropic porous medium model following the Darcy law. This was based on the physical structure of the canopy and the microenvironment of the experimental area [24]. Thus, the porous medium model simulated the resistance of the porous material to the fluid in the calculation domain by adding the source term to the momentum equation. The 


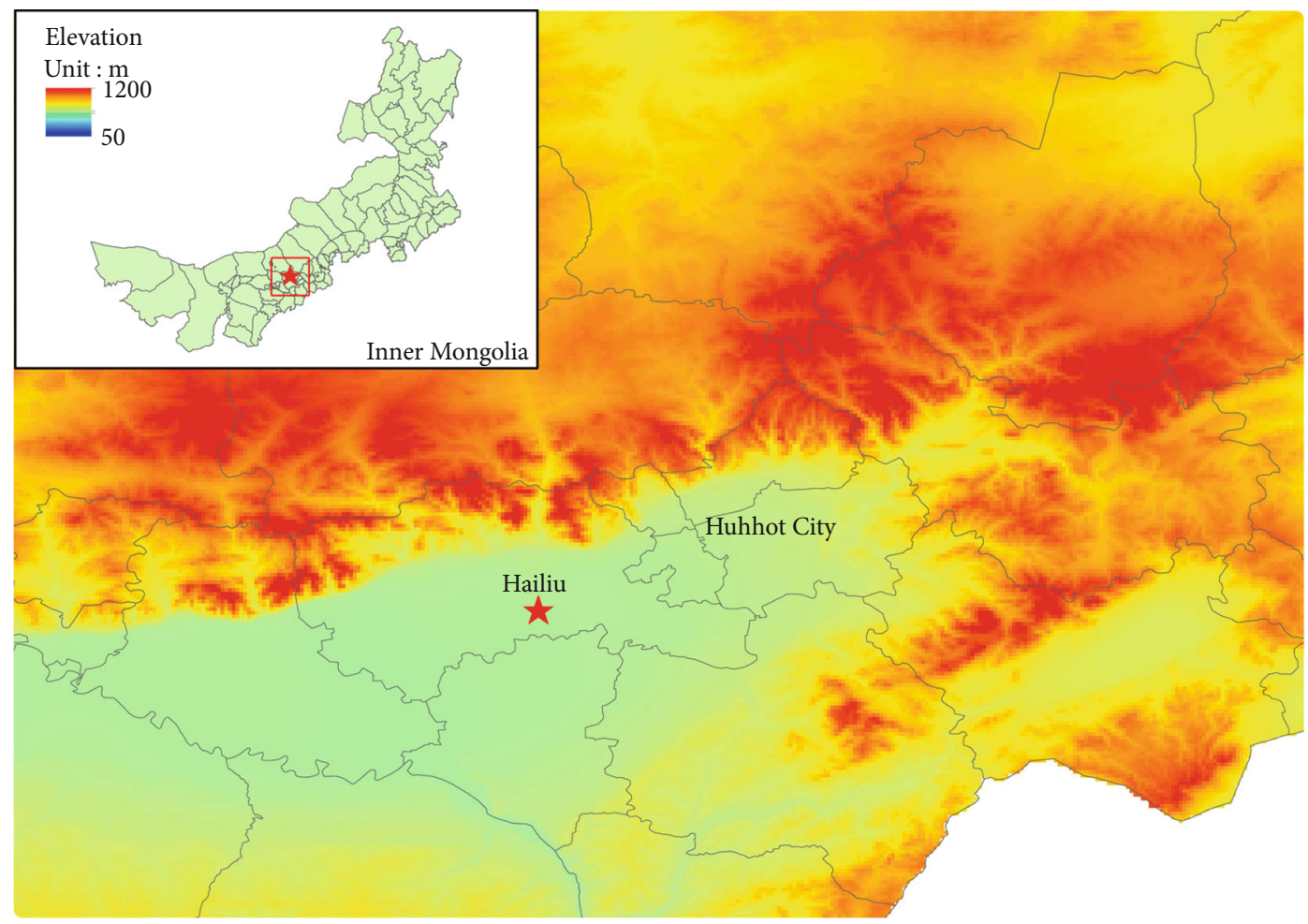

(a)

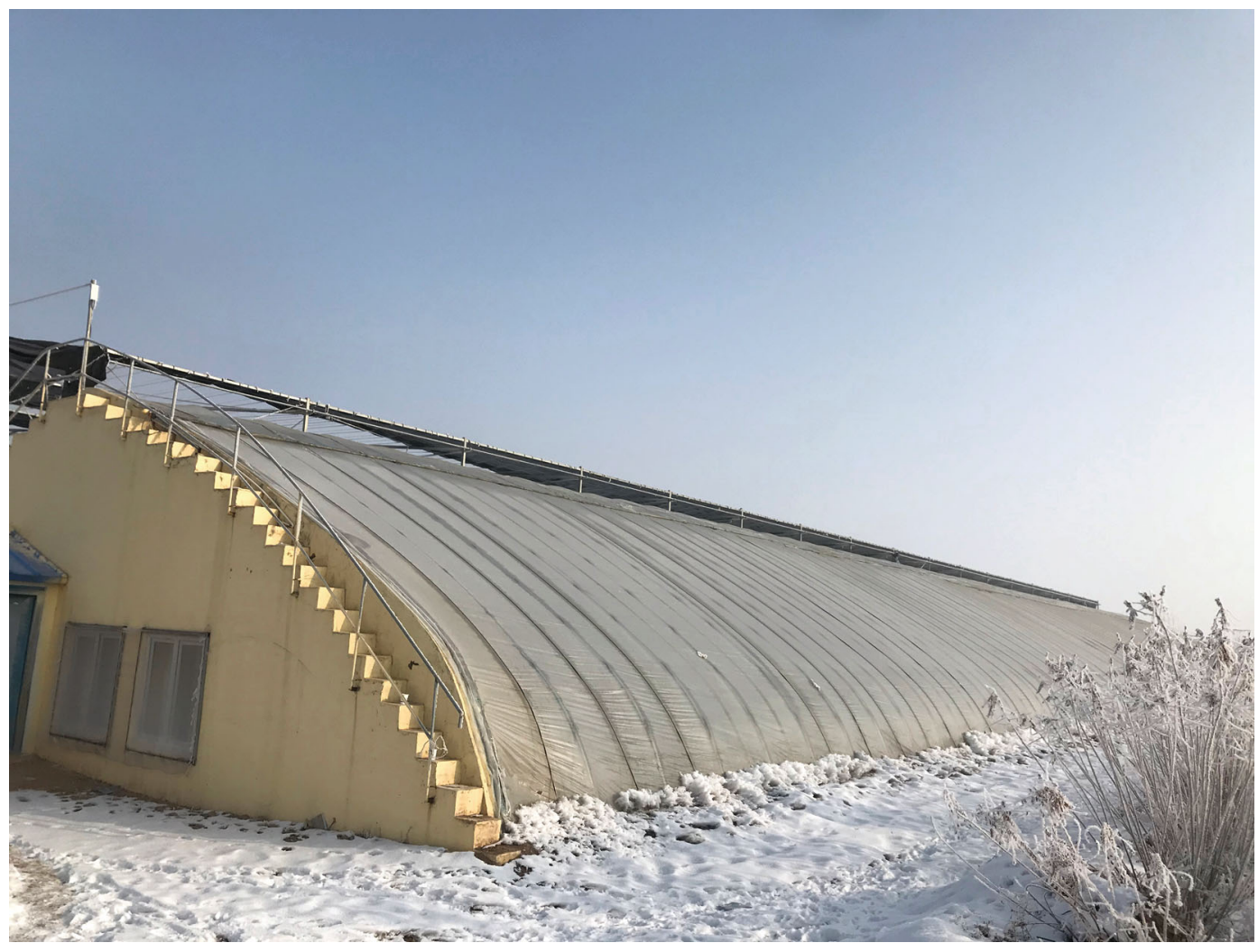

(b)

Figure 1: (a) Study site on the map of Inner Mongolia and Hohhot and (b) photograph of the greenhouse. 


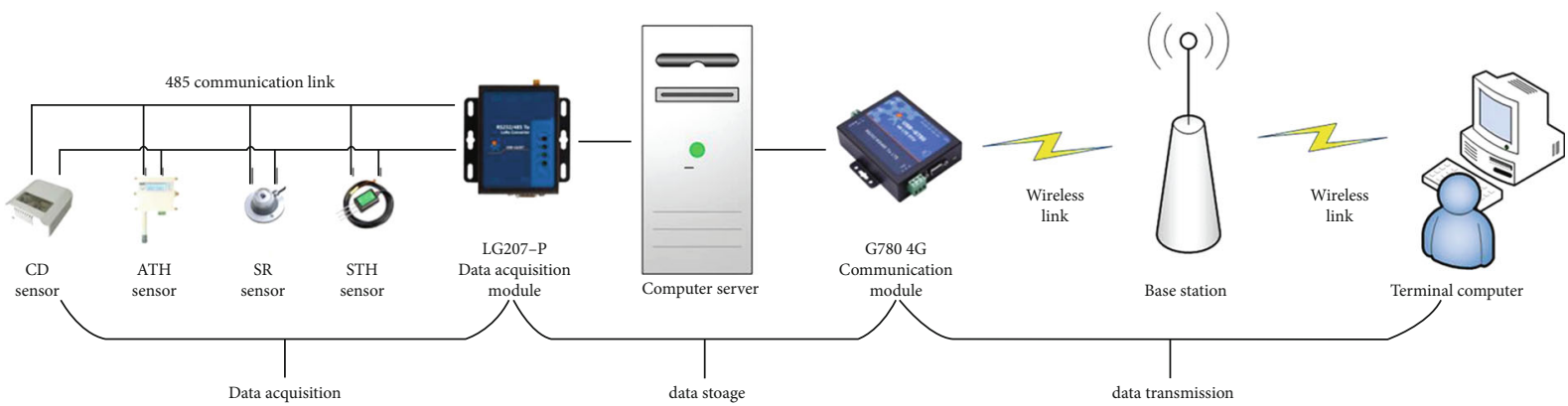

Figure 2: Connection diagram of the greenhouse sensing detection system.

source term is composed of a viscous resistance term and an inertial loss term. The apparent velocity formula of the porous medium model is as follows:

$$
S_{i}=-\left(\frac{\mu}{\alpha} v_{i}+C_{2} \frac{1}{2} \rho|v| v_{i}\right)
$$

where $S_{i}$ is the momentum source term in the $i$ direction $(x, y, z), \mu$ is the viscous coefficient, $v_{i}$ is the speed in the $i$ direction $(\mathrm{m} / \mathrm{s}),|v|$ is the absolute value of the speed, $\rho$ is the fluid density $\left(\mathrm{kg} / \mathrm{m}^{3}\right)$ in the greenhouse, $1 / \alpha$ is the viscous resistance coefficient, and $C_{2}$ is the inertial resistance coefficient. Because the fluid flow inside the canopy is laminar, the inertial resistance coefficient can be solved using the Blake-Kozeny equation:

$$
\frac{|\Delta p|}{L}=\frac{150 \mu}{D_{p}^{2}} \frac{(1-\varepsilon)^{2}}{\varepsilon^{3}} v_{\infty}
$$

where $|\Delta p|$ is the pressure gradient $(\mathrm{Pa}), L$ is the canopy thickness $(\mathrm{m}), D_{p}$ is the average particle diameter $(\mathrm{m}), \varepsilon$ is the porosity, and $v_{\infty}$ is the incoming speed $(\mathrm{m} / \mathrm{s})$. By incorporating Equation (1) into Equation (2), we obtain

$$
\begin{aligned}
\frac{1}{\alpha} & =\frac{150}{D_{p}^{2}} \frac{(1-\varepsilon)^{2}}{\varepsilon^{3}}, \\
C_{2} & =\frac{3.5}{D_{p}} \frac{(1-\varepsilon)}{\varepsilon^{3}} .
\end{aligned}
$$

In a previous study, $\mathrm{Ha}$ reported that porous media with 0.8 and $1 \mathrm{~m}$ heights had a porosity of 0.35 and 0.3 , respectively [25]. Table 1 shows the calculation results of the celery crop parameters.

By considering the viscosity of fluids in low Reynolds number flows, the renormalization group $k-\varepsilon$ turbulence model, which consider an additional term to improve accuracy [26-28], was used for the simulation. The renormalization group model equation is as follows:

$$
\frac{\partial(p u \varnothing)}{\partial t}+\operatorname{div}(\operatorname{pu} \varnothing)=\operatorname{div}\left(\Gamma_{\varnothing} \operatorname{grad} \varnothing\right)+S_{\varnothing}
$$

where the subscript $\Phi$ indicates the quantity, i.e., temperature or humidity, designated as aTp or aHd, respectively, $\Gamma_{\Phi}$ is the diffusion coefficient $\left(\mathrm{m}^{2} / \mathrm{s}\right)$, which was set as a constant, and $u$ is the fluid velocity vector $(\mathrm{m} / \mathrm{s})$.

When the solar radiance passes through the translucent film in the greenhouse, the rays are reflected and refracted. Considering the translucent film characteristics and the sunshine intensity in Inner Mongolia, the DO model was selected to simulate the effect of solar radiation on the thermal environment in the greenhouse. The Do model equation is as follows:

$$
\frac{d I(\vec{r}, \vec{s})}{d s}+K_{p} \bullet I(\vec{r}, \vec{s})=K_{p} \bullet I_{p},
$$

where $r$ is the vector direction, $s$ is the position vector, $K_{p}$ is the absorption rate of the film, $I$ is the solar radiation intensity $\left(\mathrm{W} / \mathrm{m}^{2}\right), K_{p} \cdot I$ is the solar radiant energy absorbed by the film $\left(\mathrm{MJ} / \mathrm{m}^{2}\right), K_{p} \cdot I_{p}$ is the radiant energy emitted by the film $(\mathrm{MJ})$, and $I_{p}$ is the intensity of radiation passing through the film $\left(\mathrm{W} / \mathrm{m}^{2}\right)$.

In the ANSYS Fluent simulation, the greenhouse gas was set as a mixture of water vapor and air. Energy transfer was achieved using a moisture transfer, volume fraction, and water evaporation model. From these models, we obtain

$$
\frac{\partial}{\partial t}\left(\rho c_{i}\right)+\operatorname{div}\left(p u c_{i}\right)=\operatorname{div}\left(D_{i} \operatorname{grad}\left(\rho c_{i}\right)\right)+S_{j},
$$

where $c_{i}$ is the volume concentration of component $i$ in the mixed gas $\left(\mathrm{ml} / \mathrm{m}^{3}\right), p c_{i}$ is the mass concentration of the component $\left(\mathrm{mg} / \mathrm{m}^{3}\right), D_{i}$ is the mass diffusivity of the component $\left(\mathrm{m}^{2} / \mathrm{s}\right)$, and $S_{j}$ is the additional generalized source $(\mathrm{m} / \mathrm{s})$.

2.3. Analytical Setting and Meshing Grid. We monitored the changes in the microenvironment in the central section of the greenhouse canopy. Specifically, the two-dimensional physical model in the middle section of the double-layer film solar greenhouse was established using computer-aided design and was subsequently used for the CFD simulations using ANSYS Fluent. Notably, when the same crop with high canopy height was planted without external interference, the simulation results of the middle section can represent the overall trend of the microenvironmental factors (e.g., temperature) in the greenhouse [29]. In this study, we used a 2D simulation model to monitor the distribution of the canopy microenvironment characteristics because the model 


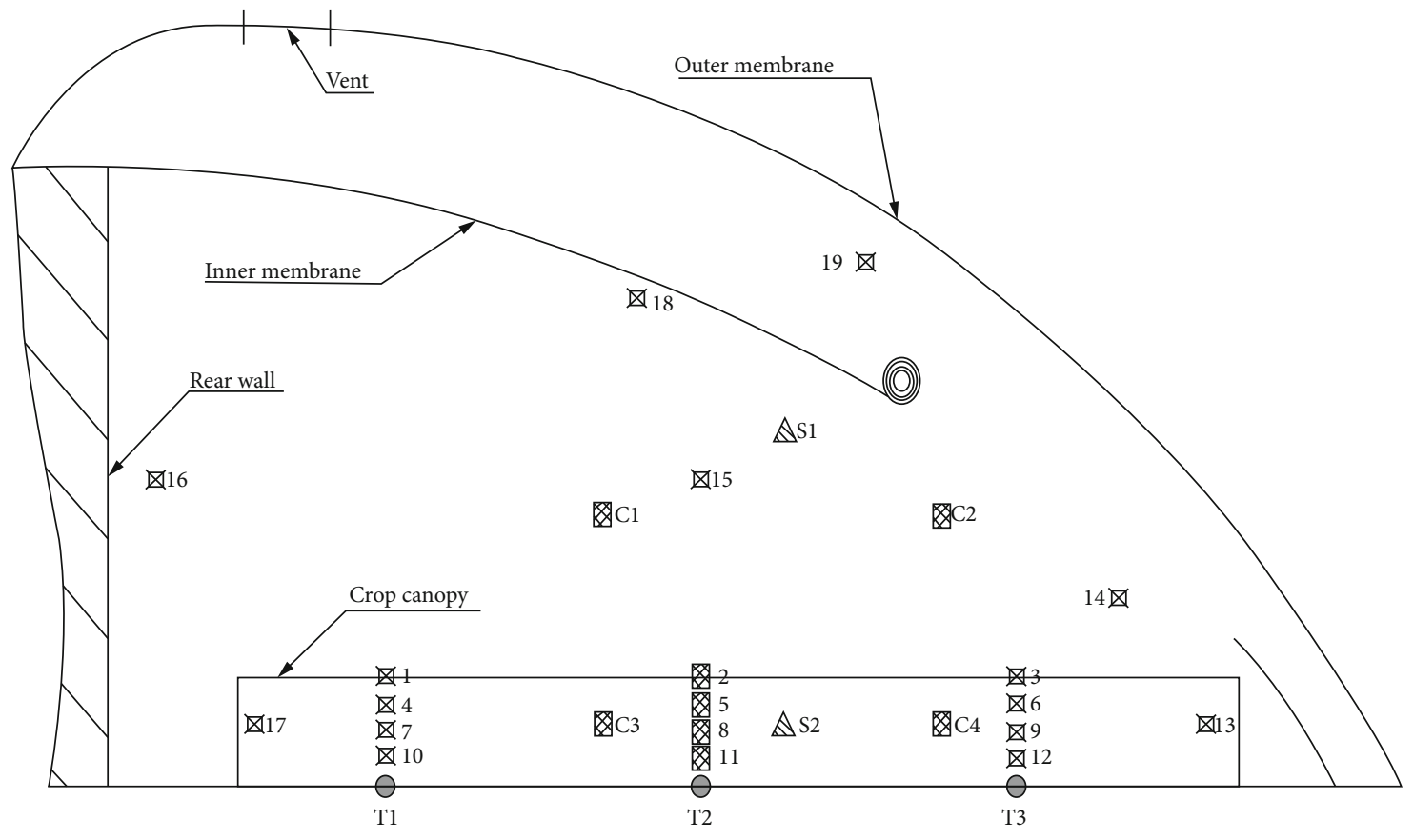
O STH sensor
ATH sensor
CD sensor
$\triangle \mathrm{SR}$ sensor

(a)

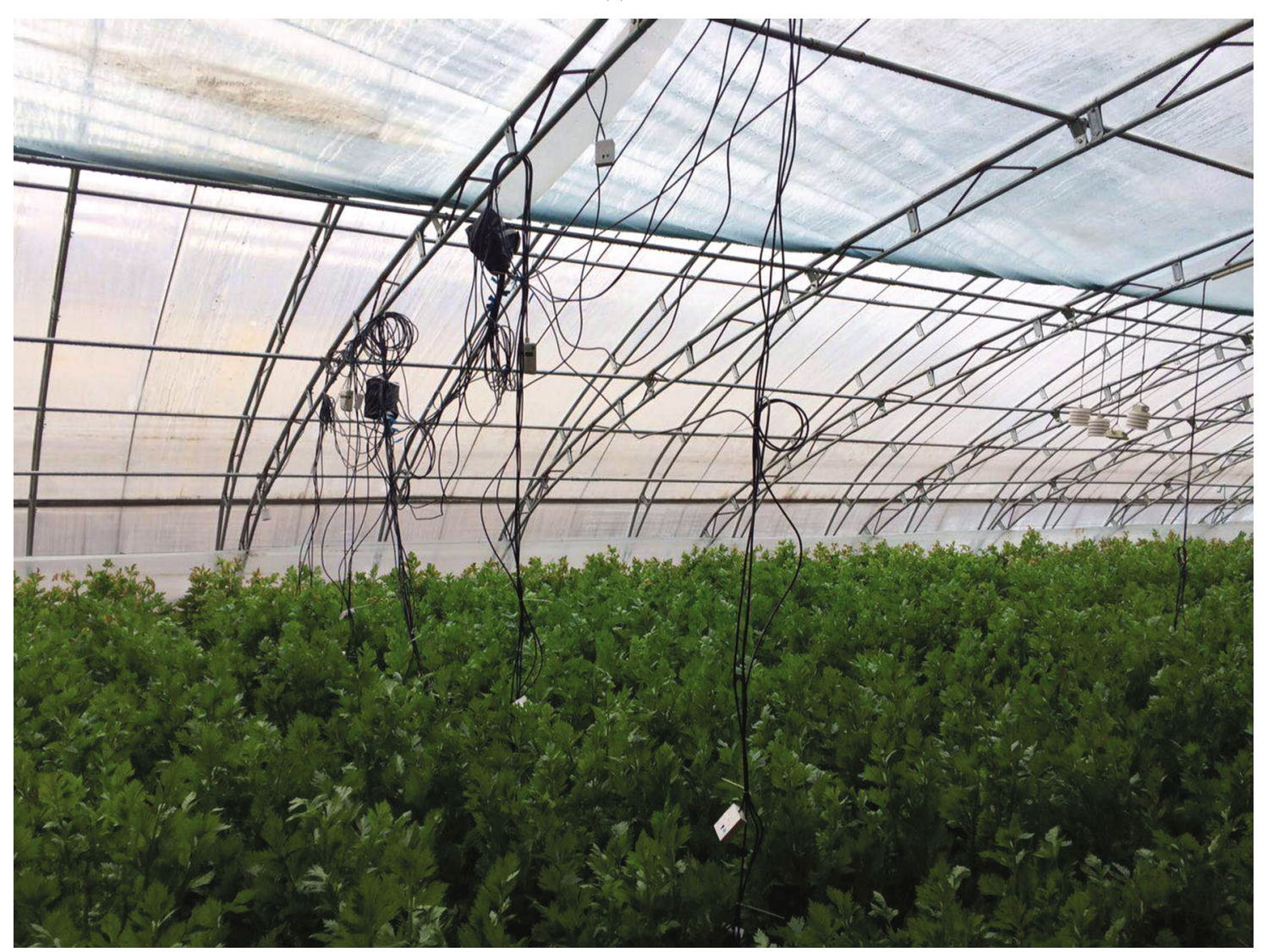

(b)

FigURE 3: (a) Arrangement of sensors in the middle section of the greenhouse and (b) photograph of the sensors in the greenhouse. 
TABLE 1: Celery porous media parameters.

\begin{tabular}{lccc}
\hline $\begin{array}{l}\text { Celery crop } \\
\text { height }(\mathrm{m})\end{array}$ & $\begin{array}{c}\text { Permeability } \\
\left(\mathrm{m}^{2}\right)\end{array}$ & $\begin{array}{c}\text { Inertial } \\
\text { resistance } \\
\text { coefficient }\end{array}$ & $\begin{array}{c}\text { Viscous } \\
\text { resistance } \\
\text { coefficient }\end{array}$ \\
\hline 0.8 & $6.766 \times 10^{-10}$ & $5.306 \times 10^{4}$ & $1.478 \times 10^{9}$ \\
1.0 & $3.674 \times 10^{-10}$ & $9.074 \times 10^{4}$ & $2.722 \times 10^{9}$ \\
\hline
\end{tabular}

could reflect the temperature and humidity distribution under the canopy with low interference and few test data. We used Jinnan Shiqin No.1 Benqin celery, which is a variety that originates from the Shandon province, China, and is widely cultivated in this region. We planted 162 rows of 11 plants of celery in the east-west direction on September 15, 2018. The growth pattern of the celery canopies with heights of $0.8 \mathrm{~m}$ (November 25, 2018) and $1 \mathrm{~m}$ (December 20, 2018) were compared. Jinnan Shiqin No.1 Benqin can grow to approximately $1.2 \mathrm{~m}$; it forms a relatively uniform-high canopy at $0.8 \mathrm{~m}$ and is suitable for harvesting at $1 \mathrm{~m}$ heights. Hence, celery heights of 0.8 and $1 \mathrm{~m}$ are the most suitable for comparison for this variety relative to having considering the porosity and other related microenvironmental factors considered in this study. The greenhouse sensor system started operating at 12:00 on September 23 and collected data every half an hour. The data were selected at 11:00 a.m. (i.e., the warm-up period in the greenhouse) and 0:00 a.m. (i.e., the cool-down period in the greenhouse) for systematic energy dynamics analysis.

In the analysis, we used CFD (ICEM-CFD) to divide the grid and calculate the simulation domain. The crop canopy area and the noncanopy air portion in the greenhouse were set as the calculation domain. The boundary of the inner and outer membrane arcs was encrypted by the grid part and subsequently discretized in the computational domain. The quality of the grid calculation was above 0.35 , and the maximum grid size was set to $0.02 \mathrm{~m}$. This setting not only enhances the accuracy of the calculation but also improves the calculation speed [30]. The temperature of the area between the inner and outer membranes was close to the outdoor temperature at night after the inner membrane was closed. Therefore, this region was ignored. We set up the same measuring point as the sensors in the ANSYS Fluent and imported the obtained measuring point data and detection data into origin for verification and analysis.

In the ANSYS Fluent solution methods, the semiimplicit method for pressure-linked equation (SIMPLE) algorithm was set to analog computing. We set the least squares cell-based for the gradient and standard for the pressure. The momentum, energy, and $\mathrm{H}_{2} \mathrm{O}$ were set to the second order upwind, turbulent dissipation rate, turbulent kinetic energy, and the DOs were set to first order upwind [31]. The underrelaxation factors of pressure, momentum, turbulent dissipation rate, and turbulent kinetic energy were set to $0.3,0.7,0.8$, and 0.8 , respectively, and the others were set to 1 . The standard of energy and DO-intensity convergence residual was set to $10^{-6}$, and the other convergence residuals were set to $10^{-3}$ [32].
2.4. Boundary Conditions. The boundary conditions included the outdoor climate, ground soil, back walls, crop area boundaries, and the inside and outside of the plastic films. The crop was set as a porous medium, and the border was set as a porous-jump boundary. The other borders were set as a wall, while the plastic films and the inner arch shed were set as translucent media [33]. Table 2 presents the thermal performance parameters of the various materials in the solar greenhouse.

\section{Results}

3.1. Energy-Flux Dynamics Simulation. Figure 4 shows the daytime and nighttime error iteration curves during the continuous-time step simulation and CFD calculation iterations. Owing to the accuracy of the model and grid settings, the error iteration curves converge quickly and smoothly. We can obtain simulation results before obtaining new test data (half an hour), so this model can be used in conjunction with the greenhouse test system to achieve real-time simulation and monitoring of the greenhouse environment throughout the day.

\subsection{Energy-Flux Dynamics Simulation. Figures 5 and 6 show} the CFD simulation results of the temperature and humidity distributions with the different celery canopy heights at 11:00 and 0:00 a.m., respectively. From Figure 5, it can be seen that at 11:00 a.m., heat is exchanged through the opening of the inner membrane, and the temperature between the inner and outer membranes reaches the highest value. The lowest temperature is measured at the bottom of the canopy layers. The temperature difference between the middle position of the 0.8 and $1 \mathrm{~m}$ high celery crop canopies, and the internal environment are 7.6 and $9.3^{\circ} \mathrm{C}$, respectively, and the corresponding lowest soil surface temperatures are 11.0 and $9.3^{\circ} \mathrm{C}$. The temperature difference in the canopy area of the $1 \mathrm{~m}$ high celery crop is larger than that in the canopy area of the $0.8 \mathrm{~m}$ high celery crop. The internal humidity of the canopy is higher than $80 \%$; it forms a gradient from the bottom to the top, with the highest humidity approaching $95 \%$. By comparing the simulated cloud maps, it can be found that the humidity distribution of the $0.8 \mathrm{~m}$ high celery canopy is similar to that of the $1 \mathrm{~m}$ high one.

From the top to the bottom of the celery canopy, the temperature decreases while the humidity increases during heating through solar radiation; in the horizontal direction (from the wall to the opening of the inner membrane), the temperature increases while the humidity decreases. These results indicate that low-porosity canopies have large differences in temperature and humidity.

Because the inner membrane was closed at 16:00, the greenhouse was in a cooling stage at night. The main sources of heat in the greenhouse were the radiant heat of the soil, walls, and crop canopy. As can be seen in Figure 6, the lowest temperature measured at night in the plastic film part near the outer soil with the 0.8 and $1 \mathrm{~m}$ high canopies is 4.9 and $5.1^{\circ} \mathrm{C}$, respectively. The highest temperature recorded at the bottom of the 0.8 and $1 \mathrm{~m}$ high crop canopies is 8.1 and $8.3^{\circ} \mathrm{C}$, respectively. The humidity inside the greenhouse 
TABLE 2: Boundary condition parameters.

\begin{tabular}{lccccc}
\hline Material & $\begin{array}{c}\text { Density } \\
\left(\mathrm{kg} \mathrm{m}^{-3}\right)\end{array}$ & $\begin{array}{c}\text { Thermal conductivity } \\
\left(\mathrm{W} \mathrm{m}^{-1} \mathrm{~K}^{-1}\right)\end{array}$ & $\begin{array}{c}\text { Specific heat capacity } \\
\left(\mathrm{J} \mathrm{kg}^{-1} \mathrm{~K}^{-1}\right)\end{array}$ & $\begin{array}{c}\text { Absorption rate } \\
(\%)\end{array}$ & $\begin{array}{c}\text { Refractive index } \\
(\%)\end{array}$ \\
\hline Plastic & 420 & 0.14 & 1380 & 0.1 & 7.5 \\
film & & 0.09 & 2512 & 0.9 & - \\
Curtain & 650 & 0.56 & 1240 & 0.9 & - \\
Wall & 1860 & 0.9 & 2010 & 0.9 & - \\
Soil & 1700 & 1.3 & 880 & 0.9 & 1 \\
Cement & 2100 & 0.023 & 1007 & - & - \\
Air & 1.29 & 0.3 & 2800 & 0.9 & 1 \\
Celery & 1070 & & &
\end{tabular}

reaches values above $90 \%$. At this time, the greenhouse is in the cooling stage, and the overall humidity difference in the greenhouse is small. The humidity in the area of the porous medium layer is the same as that inside the greenhouse. With the 0.8 and $1 \mathrm{~m}$ high canopies, the highest humidity recorded in the cover film near the southern boundary is $94 \%$ and $96 \%$, and the lowest humidity recorded near the north wall is $87 \%$ and $85 \%$, respectively. The difference in the humidity between the bottom and the area $5 \mathrm{~cm}$ above the 0.8 and $1 \mathrm{~m}$ high canopies is $1.1 \%$ and $0.5 \%$, respectively.

From the bottom to the top of the canopy, the internal temperature of the celery canopy decreases, and the humidity does not change significantly during cooling (without solar radiation). From the wall to the opening of the greenhouse (horizontal direction), the temperature increases and the humidity decreases. These results indicate that the canopy porosity and height do not affect the temperature and humidity significantly.

3.3. Simulation Verification Analysis. To verify the simulation model, we compared the simulation and measured results of the temperature and humidity with the canopies with different heights at 11:00 and 0:00 a.m. We selected the ATH sensors with number labels 2, 5, 7, 8, 9, 11, and 15 for temperature and humidity verification [34]. The horizontal and vertical temperature and humidity distributions of the crop canopy could be observed through selected measuring points. The ATH sensor No. 2, 5, 8, and 11 were used for the verification of the temperature and humidity results in the vertical direction of the canopy, while sensor No. 7, 8, and 9 were used for the verification in the horizontal direction. ATH sensor No. 15 was used as the environmental comparison point in the greenhouse. Figure 7 shows the validation results.

From the figure, it can be observed the overall trends of temperature and humidity distribution are consistent in the 0.8 and $1 \mathrm{~m}$ high canopies. Except for test point No. 9, the simulation temperature values are lower than the measured ones. The simulated humidity values at test points $2,5,7$, 8 , and 9 are lower than the measured values, while the opposite trend is observed at test points 11 and 15. At 11:00 and 0:00 a.m., the relative errors of the temperature are $7.06 \%$ and $6.64 \%$, respectively; the corresponding values of the humidity are $4.34 \%$ and 6.35 . The root mean square errors of the temperature and humidity with the $0.8 \mathrm{~m}$ high celery canopy are 0.56 and 2.86 during the day and 0.24 and 0.81 at night, respectively; the corresponding values for the $1 \mathrm{~m}$ high celery canopy are 0.51 and 2.26 during the day and 0.259 and 0.78 at night.

\section{Discussion}

The double-layer film solar greenhouse was found to control the solar radiant energy transmitted through the area between the inner and outer membranes. The opening size and time of the inner membrane were found to affect the temperature and humidity distribution of the greenhouse environment and crop microenvironment. The temperature and humidity in the crop microenvironment with the canopy structure were found to differ from the greenhouse environment. Under solar radiation, the crop canopy temperature was lower than the ambient temperature, and its humidity was higher than the ambient humidity. Boulard and Roy argued that the characteristic parameters of the porous medium on the canopy are the main factors affecting the mass and heat exchange between the crop and the environment. However, they regarded the crop canopy as a whole and studied the temperature and humidity of the canopy surface. Using advanced light modeling techniques, Zhang simulated the surface temperature of each greenhouse component and the crop at the organ level down to individual leaves. An accurate and complex modeling of crops was carried out, but the long period of simulation was not conducive to timely guidance and suggestions for crop production. $\mathrm{Xu}$ et al. developed a radiation model of a solar greenhouse and found that the temperature and humidity of the crop canopy are significantly affected by solar radiation [35]. Adeyemi used the water stress index to describe the temperature and humidity distribution characteristics of the crop canopy under irrigation conditions [36]. Xu and Adeyemi conducted research on solar radiation and water transport, respectively, but lacked analysis of canopy physical properties and model construction. Our study further verifies that the crop canopy surface effectively blocked solar radiation and that there was a difference in temperature and humidity distribution inside the canopy.

From the above mentioned studies and the results of this study, it can be concluded that under radiation, the internal temperature and humidity of the canopy are mainly affected by the canopy structure and parameters. Mass and heat were 


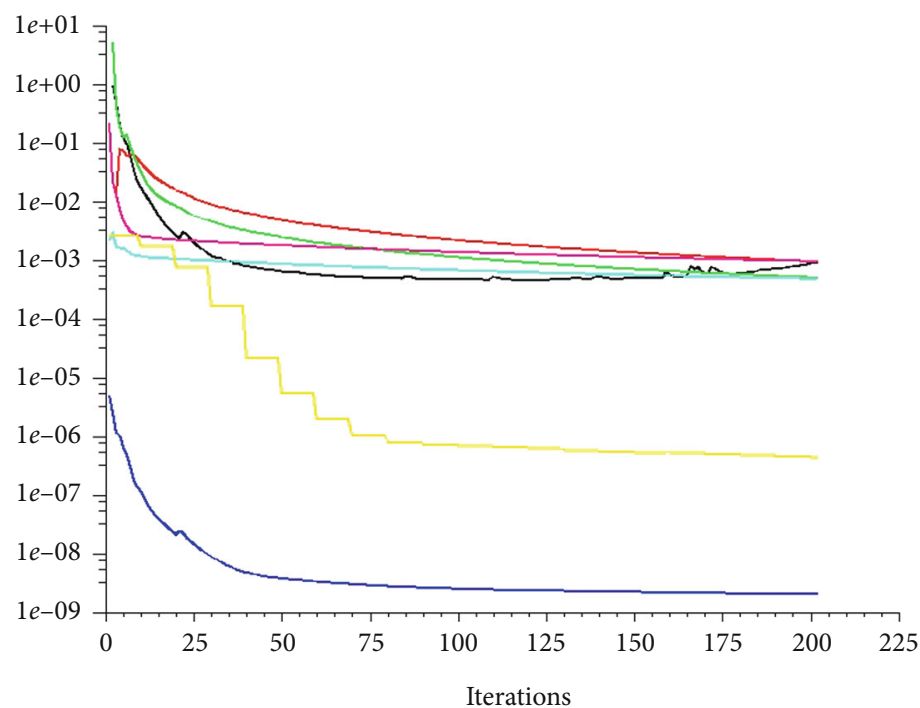

Residuals

_ Continuity

- $x$-velocity

- $y$-velocity

_ Energy

-

— Epsilon

Do-intensity

$-\mathrm{H}_{2} \mathrm{O}$

(a)

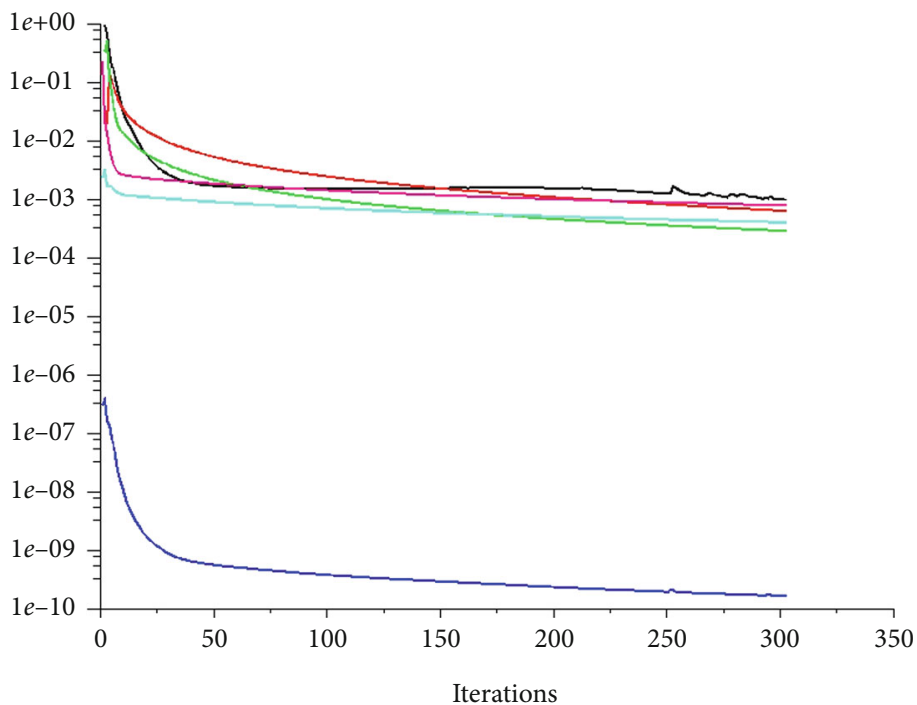

Residuals

— Continuity
$x$-velocity
$y$-velocity
Energy<smiles>[AlH]</smiles>

- Epsilon

- $\mathrm{H}_{2} \mathrm{O}$

(b)

Figure 4: (a) Daytime and (b) nighttime error iteration curves

exchanged through the canopy surface. The temperature and humidity inside the canopy formed a layered distribution according to the structure of the canopy. This suggests that the distribution of temperature and humidity can be modeled relatively easily by setting the plant porosity of crops appropriately. While some studies [37-39] reported that the crop growth can be enhanced by controlling the environmental conditions in the greenhouses, our results indicate that crops grown in the greenhouse require environmental conditions somewhat different from those of the greenhouse. Therefore, we conclude that the growth of greenhouse crops can be enhanced by setting a controlled temperature and humidity 
Contour

Static temperature

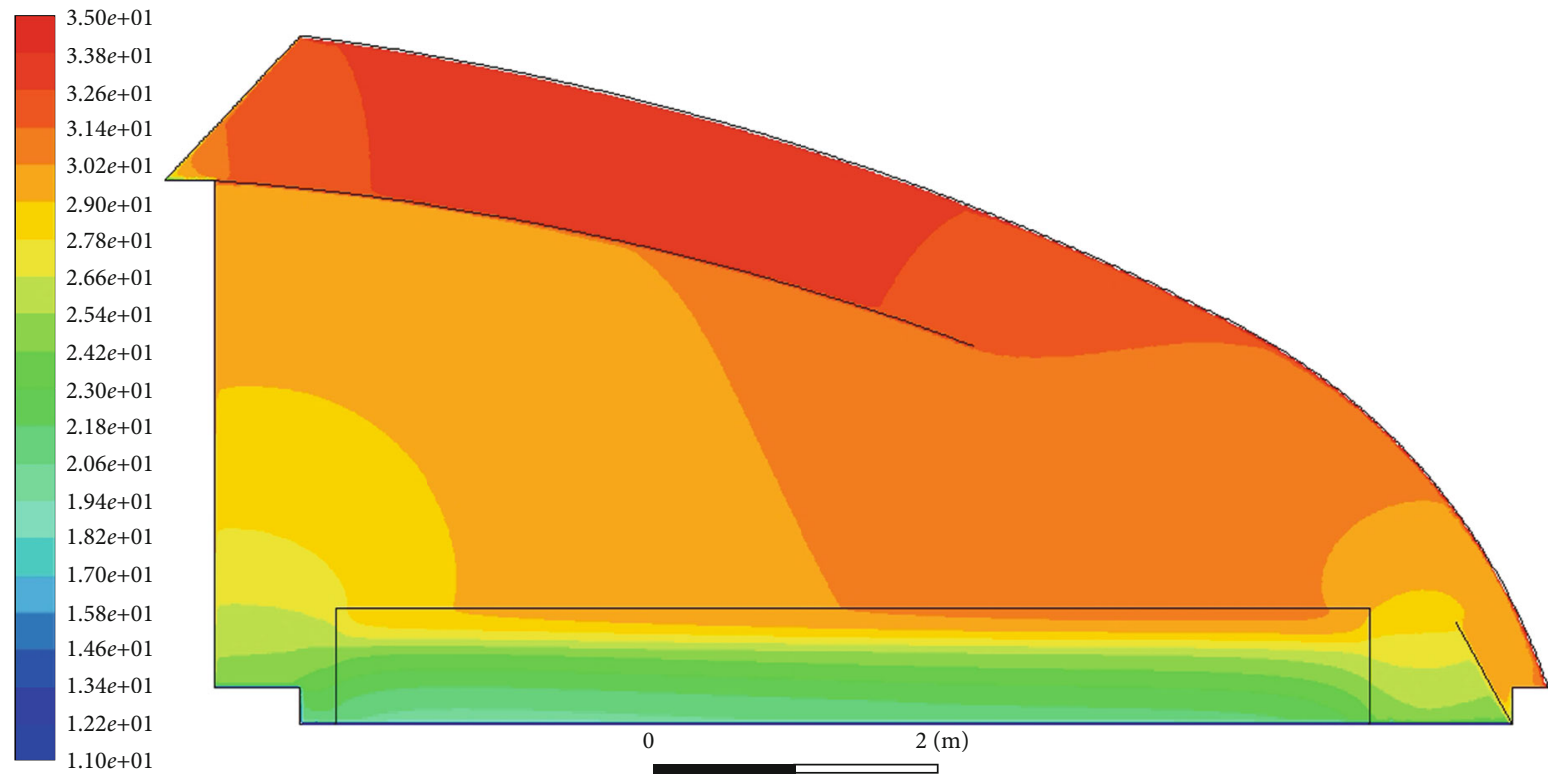

[c]

(a)

Contour

Static temperature

$3.50 e+01$

$3.38 e+01$

$3.26 e+01$

$3.14 e+01$

$3.02 e+01$

$2.90 e+01$

$2.78 e+01$

$2.66 e+01$

$2.54 e+01$

$2.42 e+01$

$2.30 e+01$

$2.18 e+01$

$2.06 e+01$

$1.94 e+01$

$1.82 e+01$

$1.70 e+01$

$1.58 e+01$

$1.46 e+01$

$1.34 e+01$

$1.22 e+01$

$1.10 e+01$

[c]

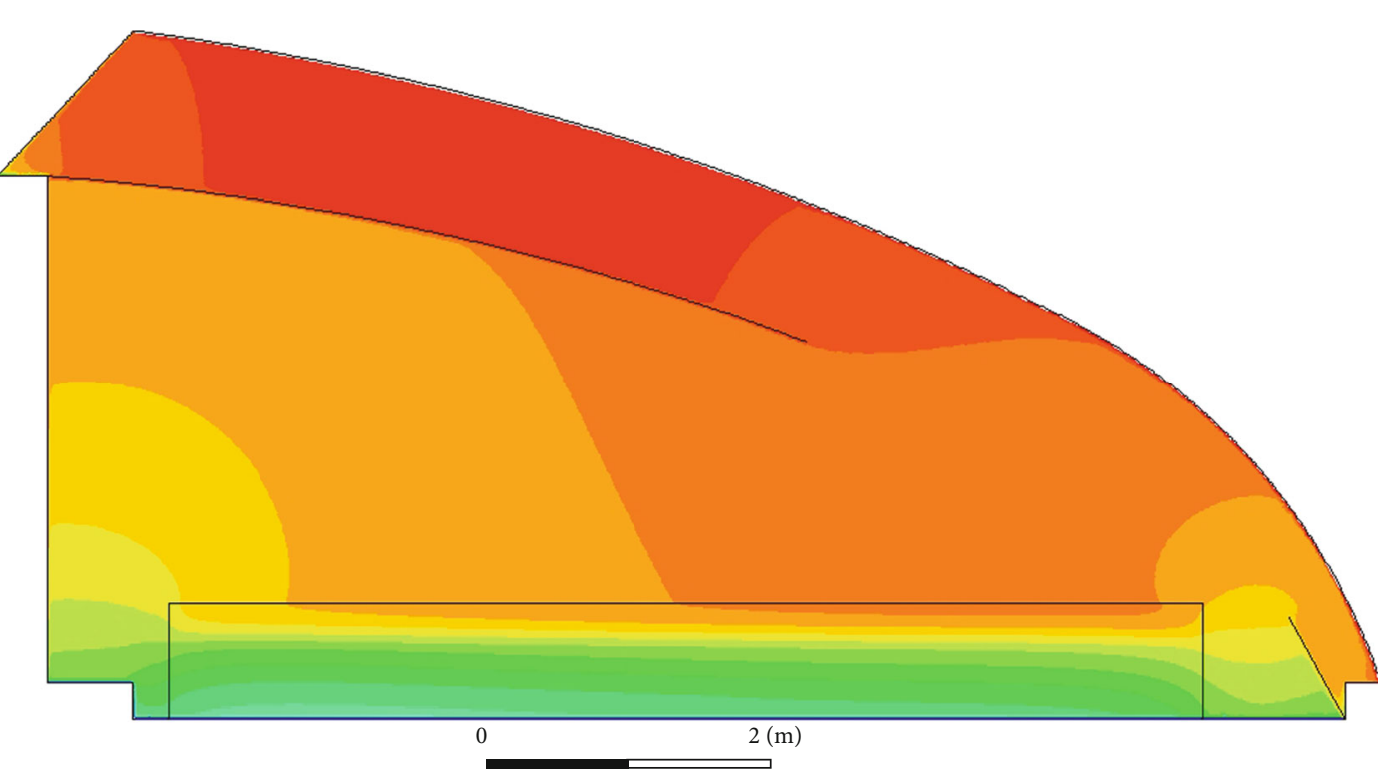

(b)

FIgUre 5: Continued. 


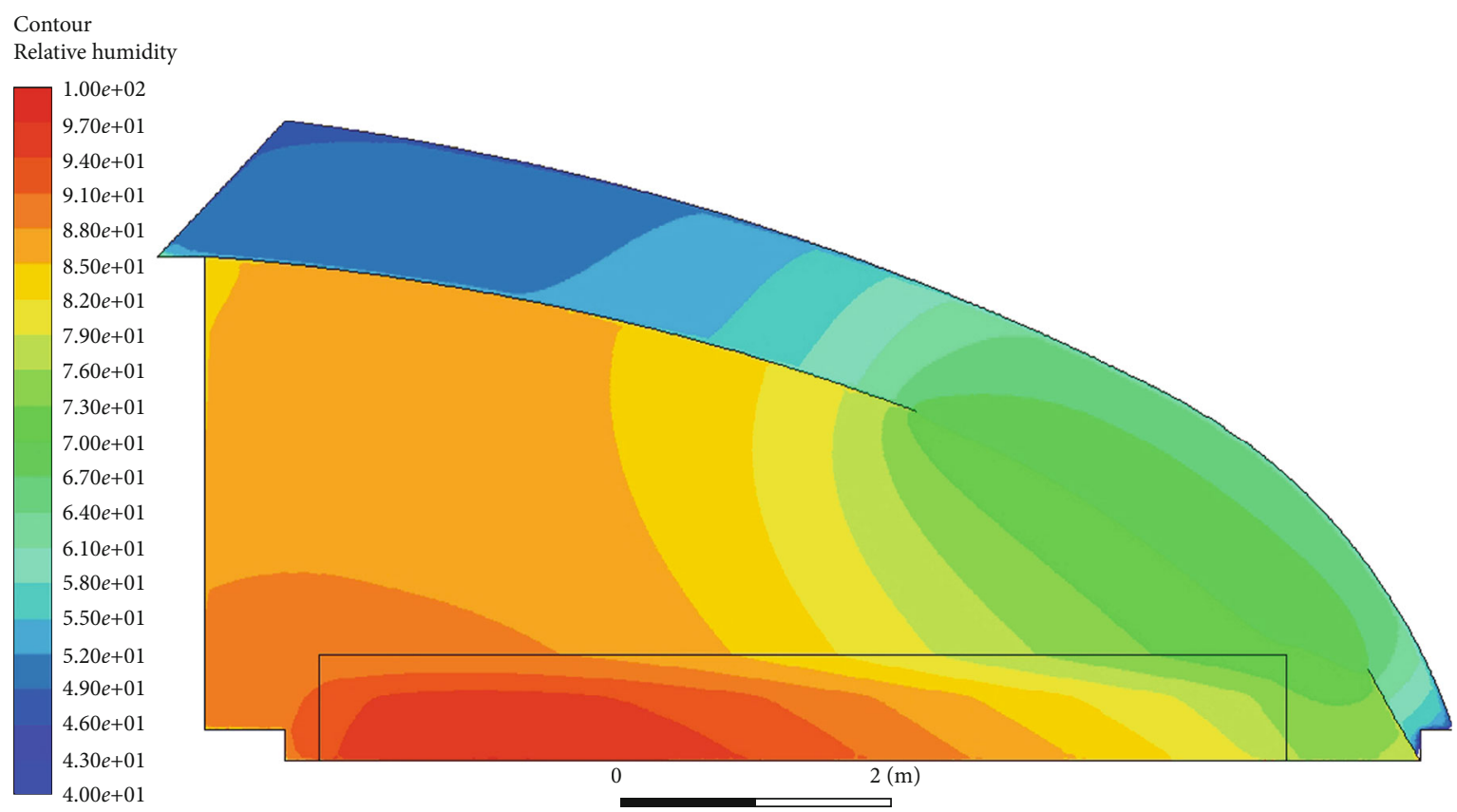

[\%]

(c)

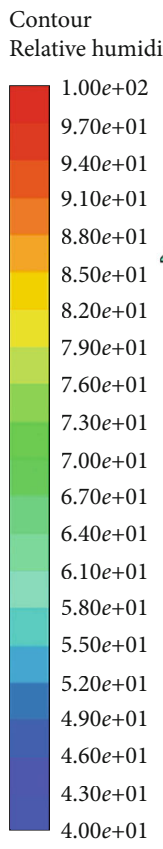

[\%]

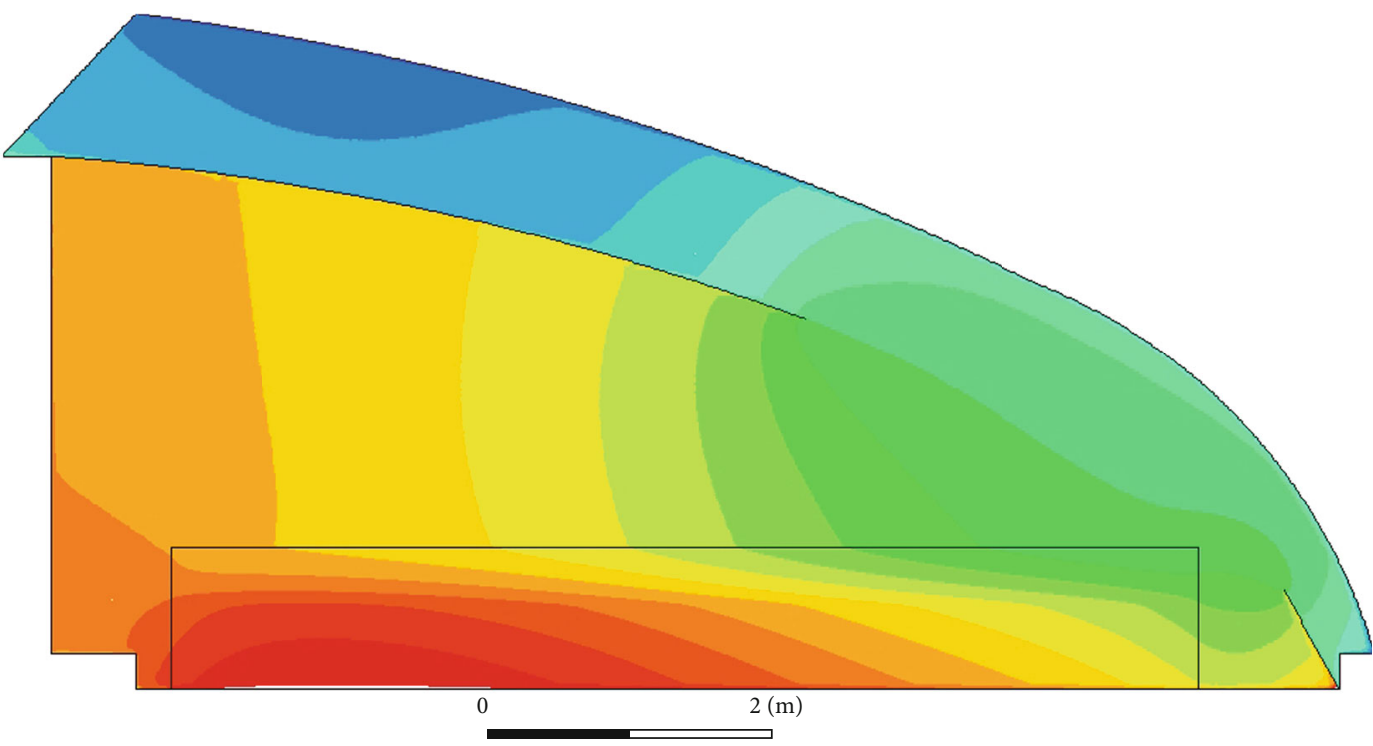

(d)

FIgURE 5: Temperature and humidity distributions at 11:00 a.m.: temperature distribution with canopy height of (a) $0.8 \mathrm{~m}$ and (b) $1 \mathrm{~m}$; humidity distribution with canopy height of (c) $0.8 \mathrm{~m}$ and (d) $1 \mathrm{~m}$.

range through the use of auxiliary equipment, such as heating, ventilation, and irrigation systems, different crop irrigation systems, and by trimming the shape of the crop canopy to facilitate light interception.

Unlike the traditional greenhouse monitoring and analysis system, the CFD simulation with the porous media canopy model can be used to record the internal microenvi- ronment status of the canopy using a greenhouse detection system. Furthermore, the CFD method allows faster collection and analysis of the results, which is important for pest control, greenhouse ventilation, irrigation, and other aspects of intensive crop production. However, there are some issues that should be investigated further. First, the porous media model uses the average porosity of the celery crop canopy, 


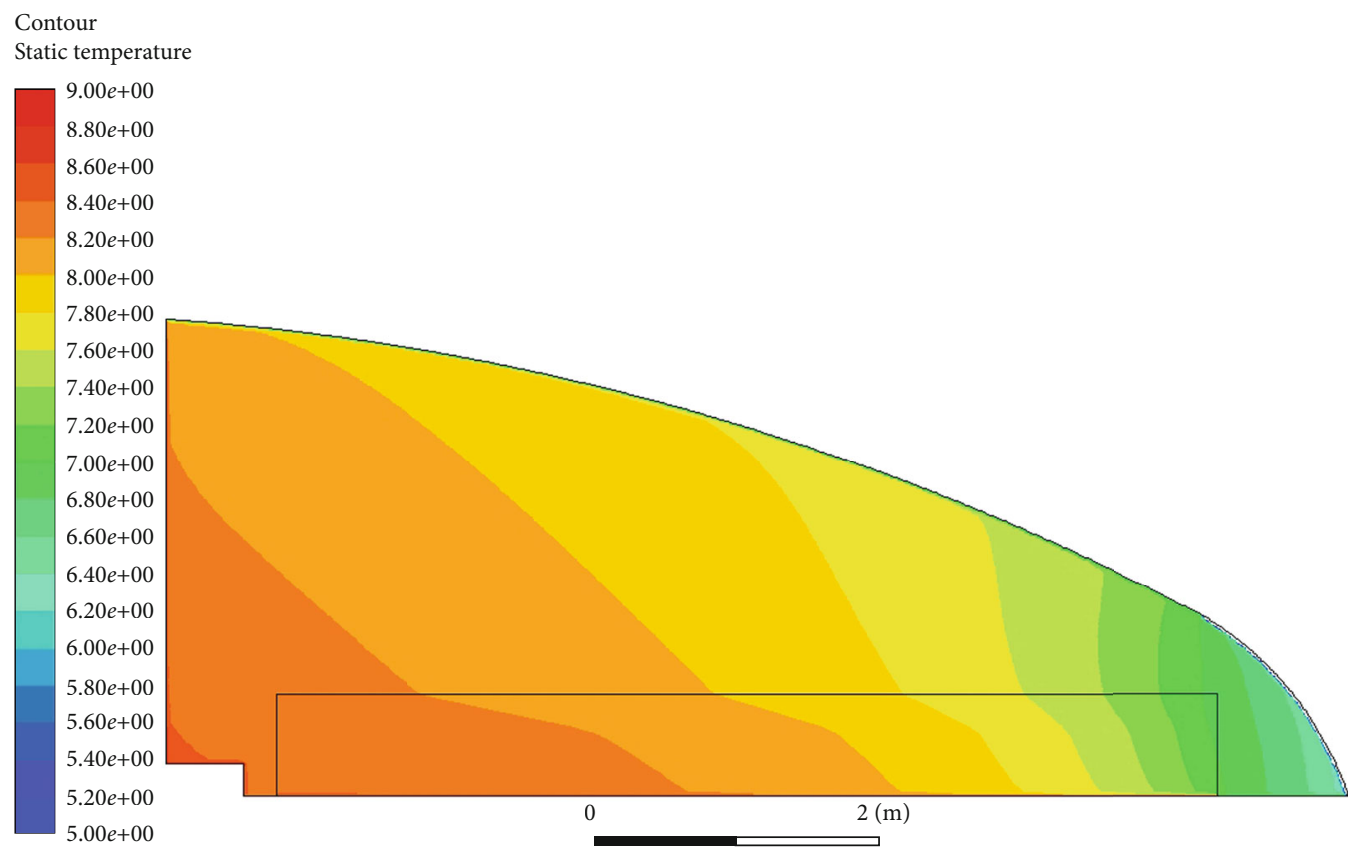

[c]

(a)

Contour

Static temperature

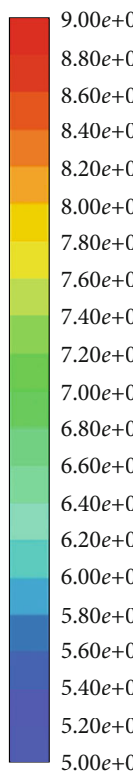

[c]

$8.80 e+00$

$8.60 e+00$

$8.40 e+00$

$8.20 e+00$

$8.00 e+00$

$7.80 e+00$

$7.60 e+00$

$7.40 e+00$

$7.20 e+00$

$7.00 e+00$

$6.80 e+00$

$6.60 e+00$

$6.40 e+00$

$6.20 e+00$

$6.00 e+00$

$5.20 e+00$

$5.00 e+00$

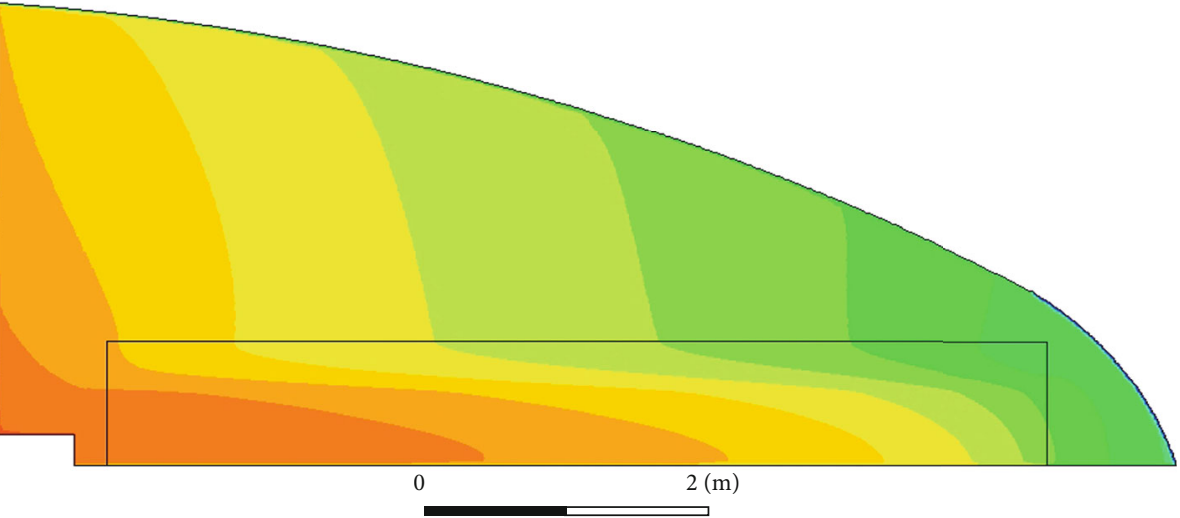

(b)

Figure 6: Continued. 


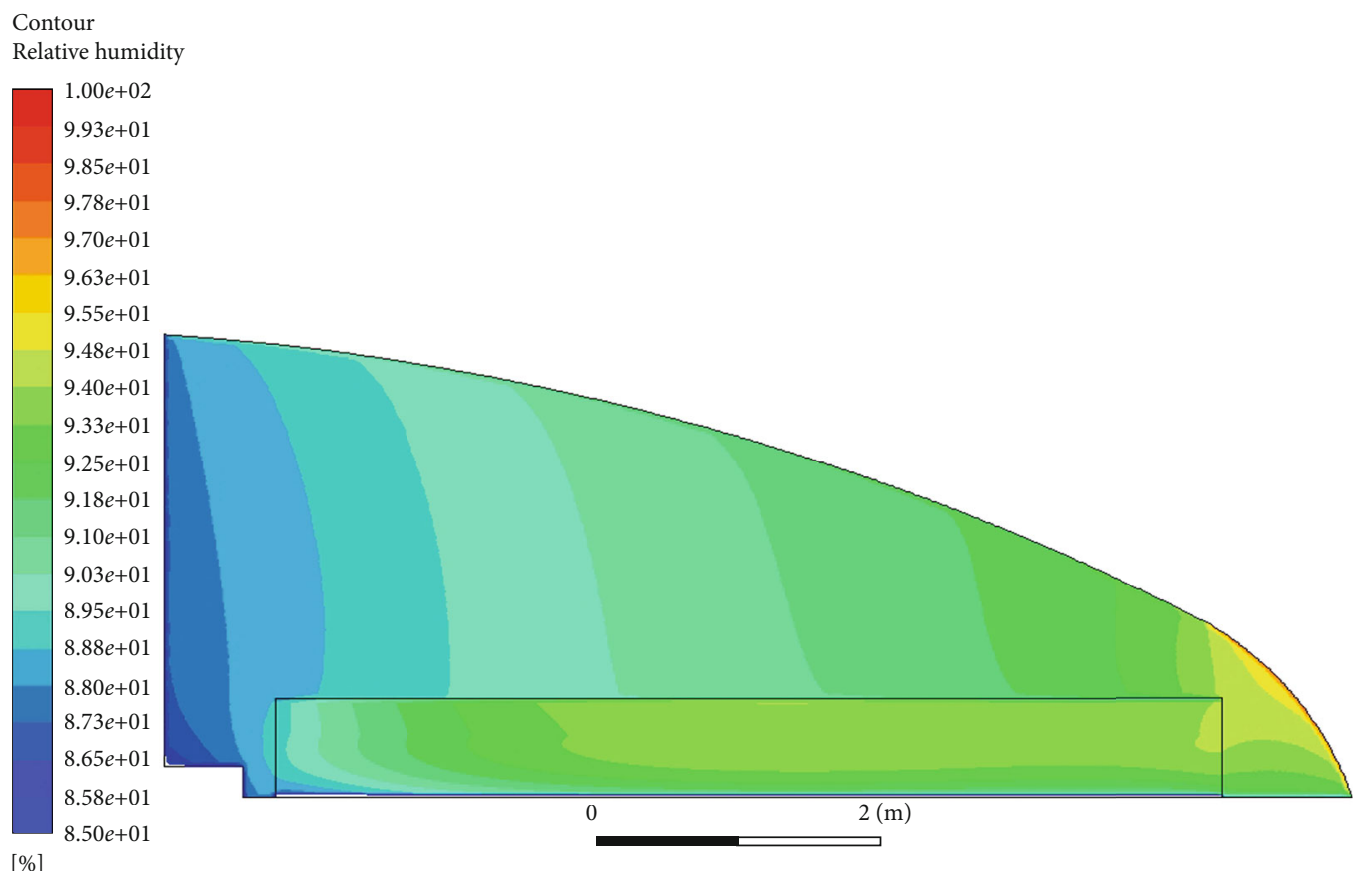

(c)

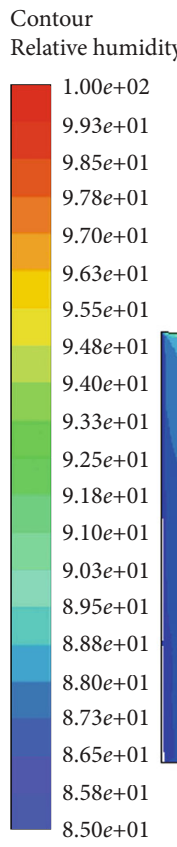

[\%]

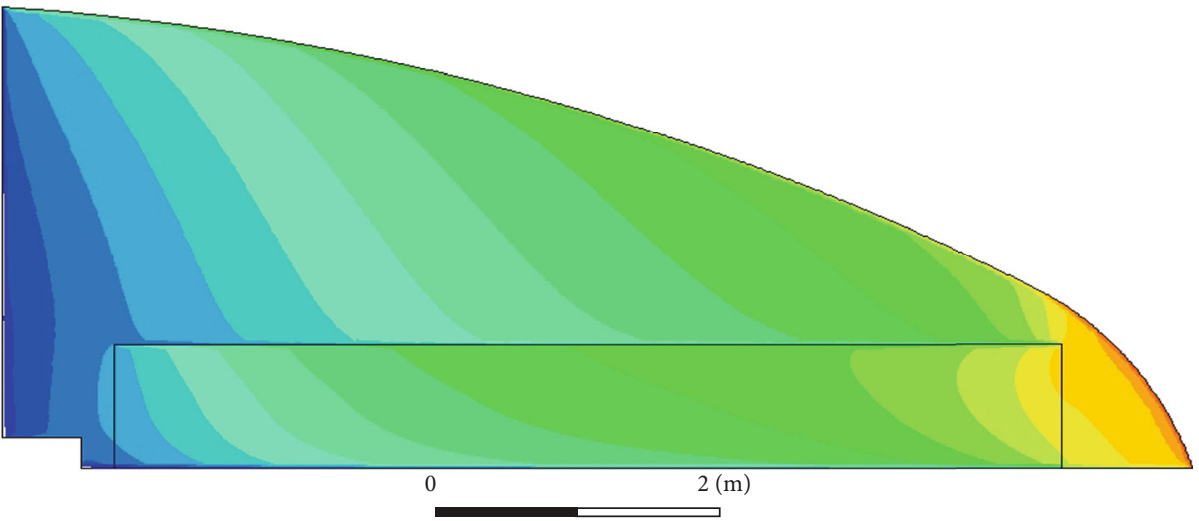

(d)

FIgURE 6: Temperature and humidity distributions at 0:00 a.m.: temperature distribution with canopy height of (a) $0.8 \mathrm{~m}$ and (b) $1 \mathrm{~m}$; humidity distribution with canopy height of (c) $0.8 \mathrm{~m}$ and (d) $1 \mathrm{~m}$.

and errors may occur in areas where the porosity varies greatly. Furthermore, the simulation regards the boundary conditions of the greenhouse environment as a whole; however, there are certain differences in space. These two issues are the main factors that cause simulation errors. Second, obtaining data through the greenhouse detection system requires human operation to import the ANSYS Fluent for CFD simulation analysis [40].
In the future, the accuracy of the simulation could be improved by dividing the canopy model into multiple combined layers with different porosities. Based on the results of this study, three-dimensional CFD simulation studies with auxiliary facilities should be carried out to further explore the spatial distribution of microenvironmental factors in a crop canopy under greenhouse conditions. 


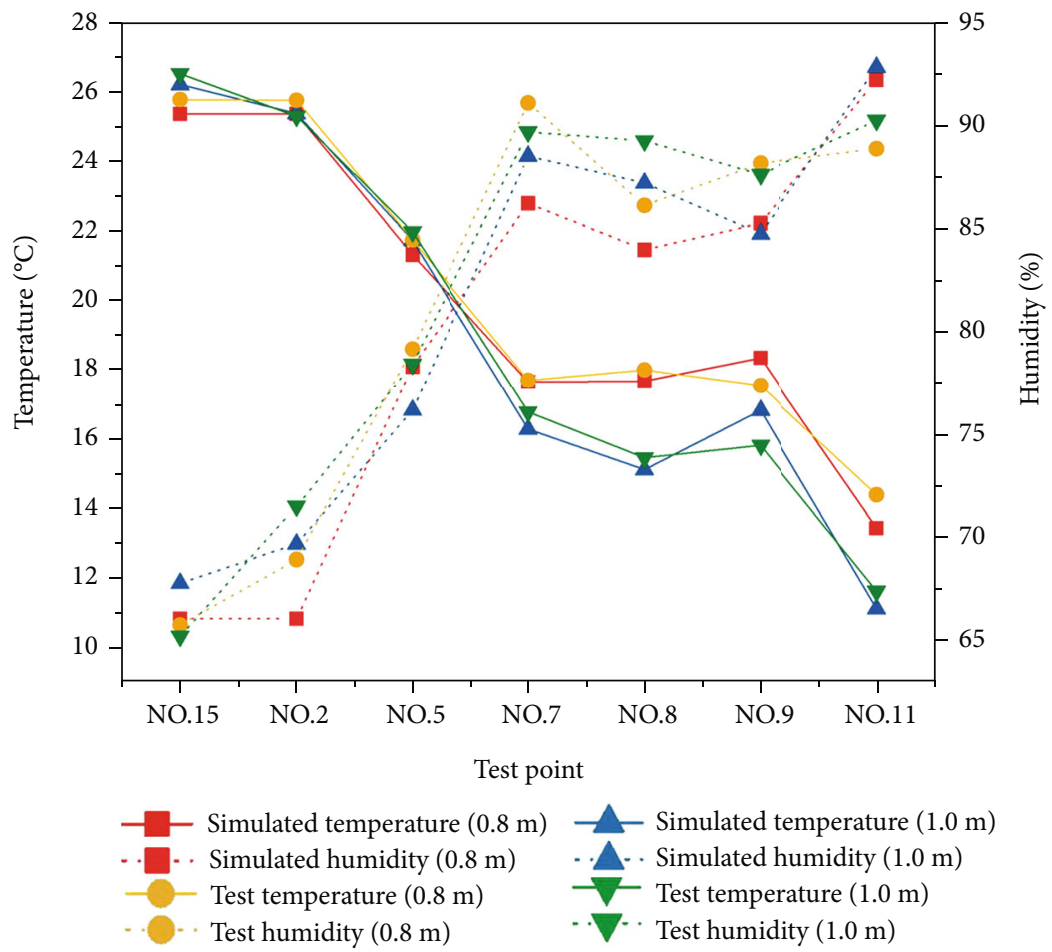

(a)

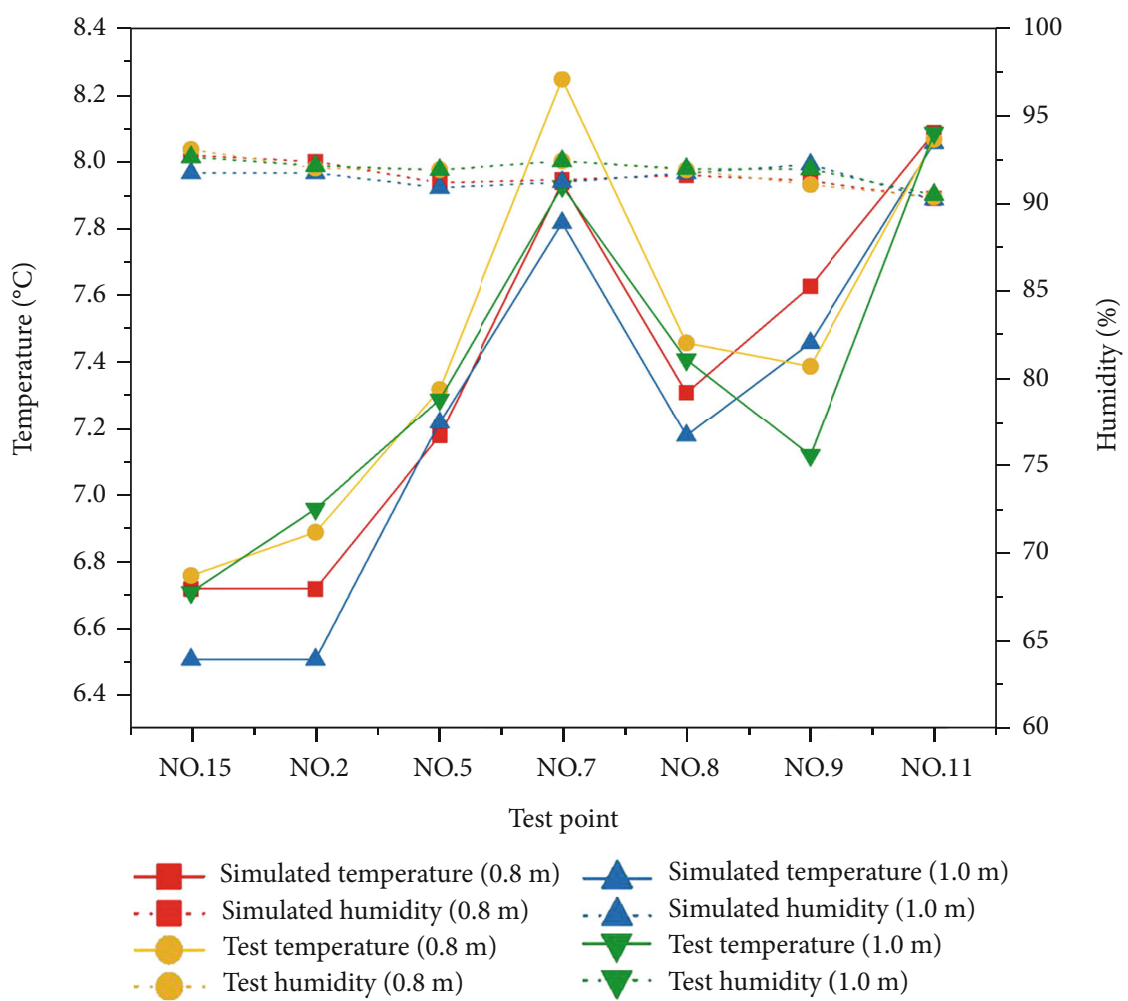

(b)

FIgURE 7: Comparison of simulated and actual measured results on temperature and humidity with canopy height of 0.8 (a) and (b) $1.0 \mathrm{~m}$.

\section{Conclusions}

We proposed a greenhouse microenvironment testing system that can monitor environmental factors (i.e., temperature and humidity) using CFD simulations with the porous media canopy model in ANSYS Fluent.

The results of this study showed that the temperature and humidity of the canopy interior changed spatially and 
differed greatly from those in the greenhouse under solar radiation conditions. The temperature and humidity of the celery canopy were found to be approximately $4-14^{\circ} \mathrm{C}$ lower and $10 \%-30 \%$ higher than those of the surroundings. As the canopy grew, the differences in temperature and humidity between the canopy and other parts of the greenhouse increased.

The porous medium model could accurately simulate the heat and mass transfer between the celery crop and greenhouse air and soil. With the simulation method proposed in this study, the production of crops in greenhouses can be modeled and digitized.

\section{Data Availability}

The raw/processed data required to reproduce the results obtained in this study cannot be shared at this time because they are used in an ongoing study.

\section{Conflicts of Interest}

The authors declare no conflicts of interest.

\section{Authors' Contributions}

Wei, J is responsible for the conceptualization, methodology, validation, resources, spatial analysis, writing (original draft preparation), writing (review and editing), visualization, and funding acquisition. Qi, L and Rui, S are responsible for the resources, writing (original draft preparation), and data curation. Lijun, $\mathrm{G}$ is responsible for the resources, software, and formal analysis. Kunyu, $\mathrm{L}$ is responsible for the resources, software, and investigation. $\mathrm{Na}, \mathrm{T}$ is responsible for the funding acquisition, writing (review and editing), and visualization. All authors approved the final version of the manuscript.

\section{Acknowledgments}

This research was funded by the National Natural Science Foundation of China (No. 61663038) and the Inner Mongolia Natural Science Foundation of China (No. 2019MS05027). The authors are grateful to the editor and reviewers for their constructive comments. We also thank Mr. Qin H, School of Energy Power and Mechanical Engineering, North China Electric Power University, for his assistance with the simulation by ANSYS Fluent and ICEM.

\section{References}

[1] G. Tong, D. M. Christopher, and B. Li, "Numerical modelling of temperature variations in a Chinese solar greenhouse," Computers and Electronics in Agriculture, vol. 68, pp. 129139, 2009.

[2] H. Fatnassi, T. Boulard, and L. Bouirden, "Simulation of climatic conditions in full-scale greenhouse fitted with insectproof screens," Agricultural and Forest Meteorology, vol. 118, no. 1-2, pp. 97-111, 2003.

[3] E. Tamimi and M. Kacira, "Analysis of climate uniformity in a naturally ventilated greenhouse equipped with high pressure fogging system using computational fluid dynamics," Acta Horticulturae, vol. 1008, pp. 177-183, 2013.

[4] A. Kichah, P.-E. Bournet, C. Migeon, and G. Chasséria, "Experimental and numerical study of heat and mass transfer occurring at plant level inside a greenhouse," Acta Horticulturae, vol. 893, pp. 621-628, 2011.

[5] C. Kittas and T. Bartzanas, "Greenhouse microclimate and dehumidification effectiveness under different ventilator configurations," Building and Environment, vol. 42, no. 10, pp. 3774-3784, 2007.

[6] F. Zhang, H. Fang, Q. C. Yang et al., "Ventilation simulation in a large-scale greenhouse based on CFD," Chinese Journal of Agrometeorology, vol. 38, no. 4, pp. 221-229, 2017.

[7] J. C. Roy, H. Fatnassi, T. Boulard, J. B. Pouillard, and A. Grisey, "CFD determination of the climate distribution in a semi closed greenhouse with air cooling," Acta Horticulturae, vol. 1170, pp. 103-110, 2017.

[8] R. Salazar, I. L. López-Cruz, A. M. Mauricio, U. Schmidt, and L. Miranda, "A physical model for water balance in a semiclosed greenhouse," Acta Horticulturae, vol. 1170, pp. 183191, 2017.

[9] J. C. Roy, J. B. Pouillard, T. Boulard, H. Fatnassi, and A. Grisey, "Experimental and CFD results on the $\mathrm{CO}_{2}$ distribution in a semi closed greenhouse," Acta Horticulturae, vol. 1037, pp. 993-1000, 2014.

[10] F. D. Molina-Aiz, D. L. Valera, and A. López, "Numerical and experimental study of heat and mass transfers in an Almeríatype greenhouse," Acta Horticulturae, vol. 1170, pp. 209-217, 2017.

[11] S. Li, D. H. Willits, and C. A. Yunker, "Experimental study of a high pressure fogging system in naturally ventilated greenhouses," Acta Horticulturae, vol. 719, pp. 393-400, 2006.

[12] P. Zhao, G. Li, and Y. Yu, "Numerical simulation and experimental study of heat and mass transfer in fuel droplet evaporation," Heat and Mass Transfer, vol. 50, no. 8, pp. 1145-1154, 2014.

[13] R. Salazar, I. López, A. Rojano, U. Schmidt, and D. Dannehl, "Tomato yield prediction in a semi-closed greenhouse," Acta Horticulturae, vol. 1107, pp. 263-269, 2015.

[14] D. Piscia, J. I. Montero, E. Baeza, and B. J. Bailey, “A CFD greenhouse night-time condensation model," Biosystems Engineering, vol. 111, pp. 141-154, 2012.

[15] T. Bartzanas, T. Boulard, and C. Kittas, "Effect of vent arrangement on windward ventilation of a tunnel greenhouse," Biosystems Engineering, vol. 88, no. 4, pp. 479-490, 2004.

[16] T. Boulard and S. Wang, "Experimental and numerical studies on the heterogeneity of crop transpiration in a plastic tunnel," Computers and Electronics in Agriculture, vol. 34, pp. 173-190, 2002.

[17] M. Teitel, M. Atias, and M. Barak, "Gradients of temperature, humidity and $\mathrm{CO}_{2}$ along a fan-ventilated greenhouse," Biosystems Engineering, vol. 106, no. 2, pp. 166-174, 2010.

[18] Y. Zhang, M. Henke, Y. Li et al., "High resolution 3D simulation of light climate and thermal performance of a solar greenhouse model under tomato canopy structure," Renewable Energy, vol. 160, pp. 730-745, 2020.

[19] R. Nebbali, J. C. Roy, and T. Boulard, "Dynamic simulation of the distributed radiative and convective climate within a cropped greenhouse," Renewable Energy, vol. 43, pp. 111$129,2012$. 
[20] A. Vergara, E. Martinelli, E. Llobet, A. D'Amico, and C. Di Natale, "Optimized feature extraction for temperaturemodulated gas sensors," Journal of Sensors, vol. 2009, Article ID 716316, 10 pages, 2009.

[21] S. Nomura, M. Arake, Y. Morimoto et al., "Thermal sensor circuit using thermography for temperature-controlled laser hyperthermia," Journal of Sensors, vol. 2017, Article ID 3738046, 7 pages, 2017.

[22] R. Zhao, G. Shao, N. Li, C. Xu, and L. An, "Development of a wireless temperature sensor using polymer-derived ceramics," Journal of Sensors, vol. 2016, Article ID 8624817, 5 pages, 2016.

[23] H. B. Ali, P. E. Bournet, V. Danjou, and C. Migeon, "CFD analysis of the climate inside a closed greenhouse at night including condensation and crop transpiration," Acta Horticulturae, vol. 1170, pp. 53-60, 2017.

[24] O. Kolditz and O. Kolditz, "Porous Media," in Computational Methods in Environmental Fluid Mechanics, International Society for Horticultural Science, 2002.

[25] T. Bartzanas, T. Boulard, and C. Kittas, "Numerical simulation of the airflow and temperature distribution in a tunnel greenhouse equipped with insect-proof screen in the openings," Computers and Electronics in Agriculture, vol. 34, pp. 207-221, 2002.

[26] S. Hussain, P. H. Oosthuizen, and A. Kalendar, "Evaluation of various turbulence models for the prediction of the airflow and temperature distributions in atria," Energy and Buildings, vol. 48, pp. 18-28, 2012.

[27] M. Córdova and B. Stoffel, "Comparison of various turbulence models in respect to their suitability for CFD calculations of diffuser flows," in Proceedings of the ASME Turbo Expo, vol. 6 PART B, pp. 1343-1353, Barcelona, Spain, 2006.

[28] M. Lateb, C. Masson, T. Stathopoulos, and C. Bédard, "Comparison of various types of $\mathrm{k}-\varepsilon$ models for pollutant emissions around a two-building configuration," Journal of Wind Engineering and Industrial Aerodynamics, vol. 115, pp. 9-21, 2013.

[29] K. Kim, J. Y. Yoon, H. J. Kwon et al., "3-D CFD analysis of relative humidity distribution in greenhouse with a fog cooling system and refrigerative dehumidifiers," Biosystems Engineering, vol. 100, no. 2, pp. 245-255, 2008.

[30] E. Santolini, B. Pulvirenti, S. Benni, L. Barbaresi, D. Torreggiani, and P. Tassinari, "Numerical study of winddriven natural ventilation in a greenhouse with screens," Computers and Electronics in Agriculture, vol. 149, pp. 41-53, 2018.

[31] Y. Li, G. Sun, and X. Wang, "Temperature field-wind velocity field optimum control of greenhouse environment based on CFD model," Mathematical Problems in Engineering, vol. 2014, Article ID 949128, 9 pages, 2014.

[32] S.-z. Liu, Y. He, Y.-b. Zhang, and X.-w. Miao, "Prediction and analysis model of temperature and its application to a natural ventilation multi-span plastic greenhouse equipped with insect-proof screen," Journal of Zhejiang University: Science, vol. 6B, no. 6, pp. 523-529, 2005.

[33] A. Kichah, P. E. Bournet, C. Migeon, and T. Boulard, "Measurement and CFD simulation of microclimate characteristics and transpiration of an Impatiens pot plant crop in a greenhouse," Biosystems Engineering, vol. 112, no. 1, pp. 22-34, 2012.

[34] J. K. Valiunas, M. Tenuta, and G. Das, “A gas cell based on hollow-core photonic crystal fiber (PCF) and its application for the detection of greenhouse gas (GHG): Nitrous oxide $\left(\mathrm{N}_{2} \mathrm{O}\right)$," Journal of Sensors, vol. 2016, Article ID 7678315, 9 pages, 2016.
[35] H. J. Xu, Y. F. Cao, Y. R. Li, J. Gao, W. J. Jiang, and Z. R. Zou, "Establishment and application of solar radiation model in solar greenhouse," Transactions of the Chinese Society of Agricultural Engineering, vol. 35, no. 7, pp. 160-169, 2019.

[36] O. Adeyemi, I. Grove, S. Peets, Y. Domun, and T. Norton, "Dynamic modelling of the baseline temperatures for computation of the crop water stress index (CWSI) of a greenhouse cultivated lettuce crop," Computers and Electronics in Agriculture, vol. 153, pp. 102-114, 2018.

[37] T. Jia, H. Y. Wang, D. Y. Chen et al., “3D temperature distribution model based on thermal infrared image," Journal of Sensors, vol. 2017, Article ID 4815021, 10 pages, 2017.

[38] T. Kuroyanagi, "Prediction of leakage rate of a greenhouse using computational fluid dynamics," Acta Horticulturae, vol. 1170, pp. 87-94, 2017.

[39] J. Chen, F. Xu, D. Tan, Z. Shen, L. Zhang, and Q. Ai, “A control method for agricultural greenhouses heating based on computational fluid dynamics and energy prediction model," Applied Energy, vol. 141, pp. 106-118, 2015.

[40] Y. Zhou, Y. Xie, and L. Shao, "Simulation of the core technology of a greenhouse-monitoring system based on a wireless sensor network," International Journal of Online Engineering, vol. 12, no. 5, pp. 43-47, 2006. 